\title{
When Subcultures Turn into Ghettos: The Conceptual Ghetto and Oppression
}

\author{
Yossra Hamouda \\ Department of Philosophy, School of Humanities and Social Sciences, the American University in Cairo, Egypt
}

Copyright $(2017$ by authors, all rights reserved. Authors agree that this article remains permanently open access under the terms of the Creative Commons Attribution License 4.0 International License

\begin{abstract}
Conceptual ghettos are closed isolated communities based on one or more prioritized aspect(s) of the individuals' identities; for example: LGBT, Muslims in Europe, African Americans in the United States and immigrants. Sometimes, the single conceptual ghetto may require more than one identity; for example: African-American LGBT Muslims. The borders between the members of the conceptual ghetto and others are not physical walls; they are rather an understanding of the self and identity. This paper addresses the question: Do Conceptual Ghettos Hinder the Decrease of Minorities' Oppression? It tries to consider whether conceptual ghettos make it more difficult to decrease the oppression of minorities or not. Literature on identity and isolation of two conceptual ghettos -LGBT and Muslims in Europe- are reviewed to examine the reasons behind the conceptual ghettoization while literature on contact hypothesis and integrated threat theory in relation to LGBT and Muslims in Europe are used to answer the paper's question. The findings of the paper show that the conceptual ghettos are the product of the oppression of the minorities and the minorities' fear of rejection and that intergroup contact is important for the support of the minorities' rights. The answer to the paper's question is that conceptual ghettos hinder the decrease of minorities' oppression. Conceptual ghettos stand against intergroup contact; they lead to the perpetuation of stereotypes, fear of the other and disagreement. They also decrease the chance of tolerance, eradicating stereotypes and supporting the minorities' rights. It is suggested that intergroup contact (both direct and mediated by a non-particularistic media) may be one way of overcoming conceptual ghettoization and decreasing oppression.
\end{abstract}

Keywords Conceptual Ghetto, Contact Hypothesis

\section{Introduction}

Conceptual ghettos are closed isolated communities based on one or more prioritized aspect of the individuals' identities, for example: LGBT, Muslims in Europe, African-
Americans in The United States and immigrants. This prioritization happens from both the individual and the society at large. Sometimes the single conceptual ghetto may require more than one identity, as with African-American LGBT Muslims. These stratified communities are not confined to geographic areas; they are rather conceptual ghettos. Geographic ghettos are closed physical areas in which individuals sharing a certain aspect of identity live, while the conceptual ghetto is a community in which individuals sharing one or more aspect of identity interact with other people of the same community far more than members of other communities. The borders between the members of the conceptual ghetto and others are not physical walls, but they are instead a conceptual understanding of the self and identity.

At first blush, conceptual ghettos seem the same as subcultures, yet this is not so according to Oxford dictionary [1], a subculture "a cultural group within a larger culture, often having beliefs or interests at variance with those of the larger culture." A subculture may be a conceptual ghetto if it is close-knit and has limited interaction with the outside world. Anime fans Otaku in The United States, for instance, are a subculture, but not a conceptual ghetto except if they experience (and practice) low close interaction with others. A subculture becomes a conceptual ghetto when the isolation from the larger culture occurs, and when the identity of the subculture becomes prioritized over other identities. As an illustration, imagine a hypothetical Egyptian Orthodox Christian subculture. Here, it would not turn into a conceptual ghetto unless Orthodox Christians define themselves as such above being Egyptians, and isolate themselves from the larger Egyptian community, so that their interaction with other Egyptians becomes distant and enforced by necessity. Such isolation can obviously occur without geographic isolation, for Orthodox Christians in Egypt can remain in the same areas as Muslims while choosing to interact on a daily basis only with other Orthodox Christians. They can have certain hospitals, shops and schools where only Orthodox Christians work. They can also choose to have most of their social interactions with other Orthodox Christians. 


\section{Why is the Concept of Conceptual Ghettos Important?}

The concept of geographic ghettos is not applicable to all cases in which the isolation of individuals sharing one or more aspect of identity occurs. As mentioned, there might be cases in which individuals sharing one or more aspect of identity become isolated from the larger society without concentrating their residence in a geographic ghetto. Many Muslims in Europe, for example, experience isolation within a small community without remaining in one closed geographic area. Muslims in Europe can and often do build strong social relationships primarily with other Muslims and in this way form their own social and cultural life that is mostly isolated from the European cultural life.

The concept of subculture is not alone capable of expressing the isolation of Muslims in Europe, for it does not necessitate isolation or explain it. That is, a subculture is not necessarily isolated, and the members of a subculture do not necessarily choose to interact more with the members of the subculture. Thus, whereas subcultures do not necessarily imply isolation, conceptual ghettos do. The concept of Conceptual Ghettos entails and encompasses the concept of subculture, but adds to it the isolation and limited interaction with the outside world. Consequently not every subculture is a conceptual ghetto, but every conceptual ghetto was (before isolation) a subculture. To oversimplify it, a conceptual ghetto is an isolated subculture with interaction with the larger society. The most distinctive characteristic of the conceptual ghetto is isolation.

The concept of conceptual ghetto is important because it helps in understanding some trends of isolation of certain communities in today's globalized world. In a society where it is possible to live physically close while having limited social interactions with those having different identities, or where one can have tight relationships with people physically far while away, we need a concept that captures more than geographic isolation. We need, that is to say, one that takes seriously what Meyrowitz and Maguire [2] called "conceptual categories" or what otherwise be understood as conceptual ghettos.

\section{The Paper's Question, the Nature of the Inquiry in this Paper, Implemented Literature and Theories (Contact Hypothesis Theory and Integrated Threat Theory)}

This paper addresses the question: Do conceptual ghettos hinder the decrease of minorities' oppression? The paper tries to consider whether conceptual ghettos make it more difficult to decrease the oppression of minorities or not. Two conceptual ghettos are examined in the paper as case studies: LGBT and Muslims in Europe. This paper is not an empirical paper; it rather uses other existing empirical studies about the reasons of isolation and ghettoization of LGBT and Muslims in Europe and the application of contact hypothesis and integrated threat theory on both case studies. The paper uses these existing studies to draw from them possible answers to the paper's question: Do conceptual ghettos hinder the decrease of minorities' oppression? This answer can be further studied and applied in later empirical research.

Part 1 of the paper seeks reasons behind the conceptual ghettoization of LGBT and Muslims in Europe by examining literature on identity and isolation of LGBT and Muslims in Europe. Part 2 of the paper reviews literature on Contact Hypothesis Theory and Integrated Threat Theory in relation to LGBT and Muslims in Europe. In Part 3, Contact Hypothesis and Integrated Threat Theory are applied to reach the answer to the paper's question. Part 4 contains the paper's conclusion and suggestions.

\subsection{Part (1): Literature on Identity and Isolation of LGBT and Muslims in Europe}

Stevens [3] examined the development of the gay identity in college environment in five categories: self-acceptance, disclosure to others, individual factors, environmental influences and multiple identity exploration. He found that gays chose to come out to close friends or other LGBT and experienced less fear of rejection from LGBT; because LGBT shares common experience of oppression. Another important finding was that gay students of colour explored their identity more; in effect, they were compelled to because they had to work through rejection of their sexuality in racial communities and prejudice against their race in LGBT communities.

Stevens' findings are important because they indicate why gays may be led to choose sexuality as an important identity and to become part of a LGBT conceptual ghetto. LGBT members experience fear of rejection and oppression; therefore they search for others who share the same experience of oppression and who are less likely to reject them. Stevens' findings about LGBT who are also racial minorities indicate why they may search for a more fragmented conceptual ghetto such as African-American LGBT members. They need others who share their experience of oppression as racial and sexual minorities and will not reject them based on their race or sexuality. Here, "oppression" and "fear of rejection" are key terms that define the identities and communication between members of the group. This suggests two reasons behind the establishment of conceptual ghettos. African-American LGBT members do not freely choose to prioritize their race and sexuality or to form a certain closed ghetto for them; it is rather the society that chooses to oppress them based on their race and sexuality. It is the society's choice of rejecting certain identities that pushes individuals to prioritize them and to be part of a conceptual ghetto based on them. The oppression and the fear of rejection are the two reasons behind the 
establishment of the LGBT conceptual ghetto.

The phenomenon of the establishment of an African-American LGBT conceptual ghetto could be explained by the model of "intersectional invisibility" that was presented in Intersectional Invisibility: the Distinctive Advantages and Disadvantages of Multiple Subordinate-Group Identities [4] by Purdie-Vaughns and Eibach. "Intersectional invisibility" was a model that showed how individuals with "intersectional subordinate-group identities" suffered from marginalization in minority groups. The model was based on the idea that there was a social prototype for race, gender and sexuality. The social prototype for race was whiteness, the prototype for gender was masculinity and the prototype for sexuality was heterosexuality. Within a community of African-Americans, the prototype was an African-American heterosexual man and within a LGBT community, the prototype was a white homosexual man. The African-American Lesbian was a non-prototype in an African-American community and also a non-prototype in a LGBT community. The "intersectional invisibility" model predicted that there were advantages and disadvantages for being a "non-prototypical".

The advantage of being an African-American woman was that prejudices about criminality were more associated with African-American men. Yet, there were costs for being an intersectional subordinate-group member. Intersectional subordinate-group members suffered from "historical, cultural, political and legal invisibilities." Their participation in historical political movements was underrepresented; they were represented less in cultural products; their causes were ignored by political movements, and the laws against discrimination were not tailored to deal with discrimination directed against individuals with an intersectional minority status. Among these four forms of disadvantages for intersectional subordinate-group members, the political invisibility is one of the most important reasons that could lead to the establishment of the more complex fragmented African-American LGBT conceptual ghetto. The political invisibility pushes African-American LGBT, according to the intersectional invisibility model- to establish a conceptual ghetto that cares to defend their rights as both African-Americans and LGBT. They try to find a place that offers recognition and respect to them and does not oppress them or ignore them because of their race or sexuality.

Husain and O'Brien [5] found many Muslims in Europe learned to compromise without losing the foundations of their religion, and adapted a more harmonious identity; yet a lot of people in the majority and minority rejected integration and adopted ideas such as "us versus them" and "our culture versus their culture." The rejection of integration of Muslims in the larger society is addressed also in Gowicharn's [6] review of When Ways of Life Collide: Multiculturalism and Its Discontent in the Netherlands by Sniderman and Hagendoorn. According to Gowicharn's reading of the work, the prejudice towards Muslims came from a fear that they were a threat to the national identity of Netherlands. This fear was also connected to a political nationalism.

The findings of Coping with Islamophobia: The effects of Religious Stigma On Muslim Minorities' Identity Formation by Kunst [7] and colleagues supported the tenet that religious stigma was an important factor behind the inability of Muslims to embrace the national identities of the European society. These findings show that the rejection of Europeans to Muslims based on their religious identity is a reason behind the embracement of Islam as the identity to the European Muslims instead of the European national identity. Here the identity of the ghetto is reinforced by stigmatization and rejection, in this case prejudice against the Muslim religious identity. Muslim Europeans find themselves forced to embrace the identity that is stigmatized because they are not accepted in the larger national identity.

Savage's [8] had similar findings, specifically that the new generation of Muslims was pushed into becoming a ghetto because of the low integration within the society, with few opportunities for work and advancement and the bias against the group. In addition to this was the fear of losing the Muslim identity as a result of integration in the larger European culture. Savage also maintained that "perceived discrimination in European societies affecting employment, education, housing, and religious practices is compelling many second- and third-generation Muslims to embrace Islam as their badge of identity" (p.31). Embracing Islam as the first identity is a basis for establishing the Muslim conceptual ghetto. In the Muslim conceptual ghetto the key to enter the closed gates of the ghetto is to be a Muslim.

These four studies give fairly clear indication that the possible ghettoization of Muslims in Europe and the rejection of some Muslims to the integration within the larger society are partially caused by stigmatization of the Muslim religious identity, the rejection of some Europeans to the integration of Muslims and oppression of and bias against them. This rejection of integration is partially caused by political nationalism and fear for the European national identity. Here, the conceptual ghetto is also caused by rejection and the rejection is caused by the fear of the other. The Oppression is again one of the main reasons behind the establishment of the conceptual ghetto of the Muslims in Europe.

\subsubsection{The Role of Technology in the Formation and Isolation of LGBT}

It is important to examine the role of technology in the formation and isolation of conceptual ghettos. Technology is an important condition in the globalization era and an important tool for different communities. The role played by technology in the formation and isolation of LGBT communities is examined by Friedman [9]. Friedman found that lesbians in Latin America escape to the internet and form their own communities online because they do not want to face the challenges of coming out in the Latin American societies. According to Friedman, the internet offers Latin American lesbians social isolation and online connections instead of offline connections. The internet also allows the 
political activism for Latin American lesbians.

Campbell's [10] results lead to similar conclusions. Campbell found that internet affinity portals like PlanetOut.com and Gay.com use the differences between gays to market their product to more audience and to gain more profit. The profit of the technology outlets relays on using the differences between gays and isolating gays more and more.

Friedman and Campbell's results show that technology plays a role in the formation and isolation of LGBT. Technology might be a factor or at least a tool in the conceptual ghettoization of LGBT.

Part (1) shows that the establishment of the conceptual ghetto in the two chosen case studies (LGBT and Muslims in Europe) is caused by the rejection and the oppression of the majority to the minority and the fear of rejection that the minority experiences. LGBT and Muslims in Europe experience oppression and they fear that the majority would reject them and this pushes them towards ghettoization within a conceptual LGBT or Muslim ghetto; they think the conceptual ghetto might accept them and might not oppress them.

An important stage in conceptual ghettoization is the prioritization of a certain aspect of identity. It is important for a Muslim to think of himself/herself as a Muslim before being European in order to become part of the Muslim ghetto in Europe. Kunst, Tajamal, Sam and Ulleberg and Savages' findings -in particular- gave a strong indication about the relationship between rejection, prioritization of a certain aspect of identity and ghettoization. These two studies showed that when Muslims experienced rejection, stigmatization and discrimination based on their national identity, they were pushed to embrace Islam as their identity instead of the European national identity. This prioritization is a fundamental stage in ghettoization; when Muslims feel that Islam is their first identity, they feel that other Muslims are closer to them than other Europeans. This makes them choose to become closer to Muslims and away from non-Muslims and this is how a Muslim conceptual ghetto is formed. A conceptual ghetto is formed when individuals choose to become closer to those who share with them a certain aspect of identity and away from those who do not share with them this aspect of identity. Part (1) also shows that Technology plays a role in the formation and isolation of conceptual ghettos like LGBT.

\subsection{Part (2): Literature on Contact Hypothesis and Integrated Threat Theory In Reference To LGBT and Muslims in Europe}

According to Oxford Reference, contact hypothesis [11] is "The proposition by the US psychologist Gordon W (illard) Allport (1897-1967) that sheer social contact between social groups is sufficient to reduce intergroup prejudice." This means that the relationships between members of different groups allow the reduction of prejudice held by different groups towards one another. And according to Stephan and Renfro [12] integrated threat theory covered four types of threats (realistic threat, symbolic threat, intergroup anxiety and stereotyping). Realistic threats are the dangers on the welfare of the group and symbolic threats are the dangers on the group values.

Contact hypothesis was supported in many studies concerning variant social groups. Pettigrew et al. [13] reviewed the advances of intergroup contact hypothesis in reference to different social groups. They found that the findings of recent researches indicated that many types of intergroup prejudice could be reduced through intergroup contact. They found that researches supported that cross-group friendships increased positive contact effect. Their most important findings were that intergroup contact lead to reducing anxiety, individual threat, collective threat and increasing intergroup trust and outgroup knowledge and empathy. Different studies indicated that intergroup contact hypothesis worked with different racial and ethnic groups as well as homosexuals, disabled and the mentally ill.

For examining the application of contact hypothesis on LGBT in particular; Garner [14] examined the relationship between contact with LGBT and support for LGBT rights and the clarity and certainty of attitudes towards LGBT rights. Garner found that the contact with LGBT positively affected the level of support for LGBT rights and also the clarity and certainty of the attitudes towards LGBT rights. He found that the stronger the degree of intimacy of contact with LGBT, the stronger the support for LGBT rights.

The integrated threat theory was tested on the prejudice towards Muslims in Netherlands in González et al.[15].It was found that half the Dutch adolescence had negative feelings towards Muslims. Most participants had very few (or no) Muslim friends. Participants perceived higher symbolic threats than realistic threats. This was connected to the focused public debate on the Muslim threat to the Dutch identity and culture, according to the researchers. The findings showed that intergroup contact reduced stereotypes and that negative stereotypes fitted best as the cause of integrated threat.

In the two previous studies; it was shown that contact with LGBT affected the attitudes towards LGBT rights and the lack of contact with Muslims in Netherland affected how the Dutch adolescence viewed Muslims as a threat. This shows that the contact with LGBT and Muslims in Europe is important for how they are viewed and how far the majority supports their rights. This means that it is better for the rights of minorities like LGBT and Muslims in Europe to have contact with the majority and to avoid imprisonment in a LGBT or a Muslim ghetto that does not allow them this close contact. If they live in a closed conceptual ghetto, they will not be able to establish close contact with the majority. This contact is fundamental because it decreases the fear of them as a threat to the larger society (in the case of Muslims in Europe) and it increases the support for their rights (in the case of LGBT). 


\section{Could Media Be a Mediator in Increasing Intergroup Contact?}

Mediated intergroup contact could play a role in reducing the fear of the other, according to Oritz and Harwood [16]. Their study showed that media could offer positive interaction and could reduce the fear of the other; because media were among the factors that affect relationships between social groups. Yet, media do not always play a positive role in intergroup contact. Media also contribute to fragmenting society and promoting ghettoization. Media are one of the factors that contribute to the establishment and strengthening of conceptual ghettos.

Dayan [17] argued that as a reaction to globalization, there was a form of "stressing particularism and reconstructing endangered identities" (p.105). He argued that particularistic media contributed to building models of identity through "clusters of media" that aimed at particularizing and caused "differentiation". However, he still argued that smaller groups within society sooner or later would be affected by ideas from the larger groups.

The role of demassification of media in dividing political points of view in society was examined by Fairweather and Rogerson [18]. They found that demassification might not be the cause of the division of the political points of view within society or widening the gap between different sects; however, it speeded up the division and added to the gap between different points of view. According to Fairweather and Rogerson, the reason was that media allowed stratified audience to listen to their point of view not to the other's point of view. They argued that stratified audience could form different ideas and huge disagreements on issues and this could not fit with a democratic society.

Fairweather and Rogerson might be mistaken in the idea that the division of political views is a negative thing because the division might be an indication of diversity. Despite this, there is an important point in their argument; stratified media do not allow audience to listen to the other which means that they do not allow mediated intergroup contact. Stratified media do not allow a group to know how the other thinks or feels and therefore, they hinder possible intergroup contact. They allow a certain group to listen only to its point of view which means that they contribute to conceptual ghettoization.

Another study conducted about a decade before Fairweather and Rogersons' study in 1996 by Mendelsohn and Nadeau [19] also showed that narrowcasting lead to more polarization. They argued that the change in media environment might cause an "opinion polarization" and might increase political cleavages so that it might become hard to speak about a "common culture." They predicted that media environment would comprise more strata of the population that are stratified based on social cleavages. They argued that their experiment suggested that regional, linguistic and ethnic cleavages might become more intense with a narrowcast media.
Meyrowitz and Maguire [2] disagreed with the negative reading of Fairweather, Rogerson, Mendelsohn and Nadeau to narrowcasting. They argued that narrowcasting did not target particular ethnicities, religions or races but rather age/sex or "lifestyle clusters" based on interests, attitudes, values and consumption pattern. They argued that the target audience was not "traditional groups" but rather "conceptual categories." They used the example of Hispanic television and argued that it reduced differences and ignorance within the Hispanic population. They made the argument that current media blended the old local identities with the traditional notions of national identity and made them one society. Despite this, they admitted that subcultures' appearance on TV made everyone aware of the differences that had always existed. "Change in media and in our sense of place is leading us to become newly strange and newly familiar to each other" (p.48)

The problem with Meyrowitz and Maguires' reading to narrowcasting is that they underestimated the impact of the fragmentation based on "conceptual categories". Fragmentation based on "conceptual categories" is not different from fragmentation based on ethnicity and race in its impact on the isolation within society. Both are forms of establishing certain ghettos within society that lack interaction and intergroup contact. When media participate in fragmentation rather than intergroup contact, media turn into a force that pushes subcultures towards turning into conceptual ghettos rather than decreasing the gap of misunderstanding between groups through intergroup contact. Fragmented media push towards ghettoization rather than integration.

\section{Do Conceptual Ghettos Reduce Intergroup Contact?}

In Localizing Islam in Europe: Turkish Islamic Communities in Germany and the Netherlands; Yükleyen [20] argued that Islamic communities in Europe can both integrate and isolate Muslims according to their social structures and level of inclusiveness in their discourse. He argued that Islamic communities that used exclusive discourse and possessed exclusive religious discourse isolate their followers from the larger society (254). Here, certain forms of Islamic communities cause ghettoization and isolation. Islamic communities are not always isolated by definition, yet, certain forms of Islamic communities approach ghettoization and isolation. These Islamic communities turn from a subculture to a conceptual ghetto when they use exclusive religious discourse and isolate their followers. This isolation hinders intergroup contact. Here, the Muslim conceptual ghetto in Germany and the Netherlands lead to reducing intergroup contact.

\subsection{Part (3): Answering the Paper's Question: Do Conceptual Ghettos Hinder the Decrease of Minorities' Oppression?}


Part (1) of the paper showed that the oppression and the fear of rejection were the reasons for forcing LGBT and Muslims in Europe into conceptual ghettoization. It also showed that technology can play a role in the formation and isolation of conceptual ghettos. Part (2) of the paper showed that the contact with LGBT increased the support for LGBT rights from the majority and that the low contact between Muslims in Netherlands and the majority caused the majority of the Dutch adolescence to view Muslims as a threat. Part (1) and part (2) together showed that the conceptual ghettos are the product of the oppression and the fear of rejection and they also showed that intergroup contact is important for the support of the minorities' rights. Conceptual ghettos are the result of the oppression and the fear of rejection but they also stand against intergroup contact.

Conceptual ghettos are defined in this paper as; "closed isolated communities based on one or more prioritized aspect of the individuals' identities... They are communities in which individuals interact with other members of the same community far more than members of other communities." They do not allow close intergroup contact because of their structure. They are structured to only accept individuals sharing a certain aspect of identity together. They are not structured to allow the other to enter them and to interact with the members of the conceptual ghetto. This makes conceptual ghettos an obstacle in front of intergroup contact. And since intergroup contact is fundamental for the support of minorities rights (as shown with supporting LGBT rights); therefore, conceptual ghettos are obstacles against the support of minorities rights. Therefore; conceptual ghettos hinder the decrease of minorities' oppression.

The argument for answering the paper's question could be summarized as follows:

Premise 1: Intergroup contact whether direct or mediated by media leads to more tolerance, less stereotyping and more support for minorities' rights while lack of intergroup group contact and promotion of particularization through media leads to the perpetuation of stereotypes, fear of the other and disagreement.

Premise 2: Conceptual ghettos hinder intergroup contact as they isolate their members from the larger society (like the case of Islamic communities with exclusive discourse). As the walls of the conceptual ghettos grow thicker, individuals within these ghettos reduce their interaction with others outside the ghetto and become more isolated. As conceptual ghettos strengthen, intergroup contact weakens.

Conclusion: Conceptual ghettos lead to the perpetuation of stereotypes, fear of the other, disagreement and decrease the chance of tolerance, eradicating stereotyping and support for minorities' rights. Therefore, conceptual ghettos hinder the decrease of minorities' oppression.

\subsection{Part (4): Conclusion, Limitations and Suggestions}

This paper introduced the concept of conceptual ghetto and defined it as "closed isolated communities based on one or more prioritized aspect of the individuals' identities". The paper examined the reasons behind conceptual ghettos through reviewing literature on two conceptual ghettos (LGBT and Muslims in Europe). It attempted answering the question: Do Conceptual Ghettos Hinder the Decrease of Minorities' Oppression? This paper was not an empirical paper; it rather used existing empirical papers about the reasons of isolation and ghettoization of LGBT and Muslims in Europe and the application of contact hypothesis and integrated threat theory on both case studies to answer the paper's question. It was found that conceptual ghettos lead to the perpetuation of stereotypes, fear of the other, disagreement and decrease the chance of tolerance, eradicating stereotyping and support for minorities' rights. The theoretically proposed answer to the paper's question was that conceptual ghettos hinder the decrease of the minorities' oppression.

This answer needs further empirical studies to support or reject it. The lack of empirical research could be a limitation to this theoretical paper and to the theoretical answer to the paper's question. Further empirical research is recommended to examine the possible role of conceptual ghettos in hindering the decrease of the minorities' oppression. This paper offered a theoretical answer that needs to be supported or rejected by later empirical research.

As Dayan [17] hinted, the stressing of particularism and reconstructing of endangered identities are reactions against globalization. The stressing of particularism may continue growing and the isolation of individuals within smaller and smaller ghettos may increase as well; especially with the increase of a narrowcast media that propagates ghettoization. This means that the conceptual ghettos may grow stronger and their conceptual walls may also grow thicker. As the paper showed, the conceptual ghettos stand against intergroup contact and hinder the decrease in stereotyping and the support for minorities' rights.

What we need is that media shift from demassification to a contribution to intergroup contact. Media shall not target mainstreaming opinion and preventing people from thinking differently or adopting a different identity but it shall not also target certain groups and show them what they want to see. Media shall be the media for intergroup contact.

\section{REFERENCES}

[1] Oxford Dictionaries. Subcultures. Available from: http://www.oxforddicitionaries.com/definition/English/subcul ture [Accessed 25th Mar. 2016].

[2] Meyrowitz, J., \& Maguire, J. Media, Place, and Multiculturalism. Society, (1993); 30(5): 41-48.

[3] Stevens, R. A Understanding Gay Identity Development Within the College Environment. Journal of College Student Development, (2004); 45(2): 185-206. 
[4] Purdie-Vaughns, V., \& Eibach, R. P. Intersectional invisibility: The distinctive advantages and disadvantages of multiple subordinate-group identities. Sex Roles, (2008); 59(5-6): 377-391.

[5] Husain, F., \& O'brien, M. Muslim Communities in Europe: Reconstruction and Transformation. Current Sociology, (2000); 48(4): 1-13.

[6] Gowricharn, R. When Ways of Life Collide: Multiculturalism and Its Discontents in the Netherlands. Journal of Multilingual and Multicultural Development (2009); 30(2): 177-179 Available from: doi: 10.1080/01434630802361137.

[7] Kunst, J. R., Tajamal, H., Sam, D. L., \& Ulleberg, P. Coping with Islamophobia: The effects of religious stigma on Muslim minorities' identity formation. International Journal of Intercultural Relations, (2012); 36(4): 518-532.

[8] Savage, T. M. Europe and Islam: Crescent Waxing, Cultures Clashing. The Washington Quarterly (2004); 27(3): 25-50. The MIT Press. Available form: from Project MUSE database. Accessed: 18th July 2016.

[9] Friedman EJ. Lesbians in (cyber) space: the politics of the internet in Latin American on-and off-line communities. Media, Culture \& Society. 2007 Sep; 29(5): 790-811.

[10] Campbell JE. Outing PlanetOut: surveillance, gay marketing and internet affinity portals. New media \& society. 2005 Oct; 7(5): 663-83.

[11] Oxford Reference. Contact Hypothesis. Available from: http:/ /www.oxfordreference.com/view/10.1093/oi/authority.20110 803095634484. [Accessed. 1st April 2016].

[12] Stephan, W. G., \& Renfro, C. L. The Role of Threat In Intergroup Relations. In: Mackie D. M., Smith E. R. (eds.)
From Prejudice to Intergroup Emotions: Differentiated Reactions to Social Groups, United Kingdom: Psychology Press; (2002). p. 191-207.

[13] Pettigrew, T. F., Tropp, L. R., Wagner, U., \& Christ, O. Recent Advances in Intergroup Contact Theory. International Journal of Intercultural Relations, (2011); 35(3): 271-280. Available from: doi:10.1016/j.ijintrel.2011.03.001.

[14] Garner, A. Ambivalence, the Intergroup Contact Hypothesis, and Attitudes About Gay Rights. Politics \& Policy, (2013); 41(2): 241-266. Available from: doi:10.111/polp.12010.

[15] Velasco González K, Verkuyten M, Weesie J, Poppe E. Prejudice towards Muslims in the Netherlands: Testing integrated threat theory. British Journal of Social Psychology. 2008; 47(4):667-85.

[16] Ortiz, M., \& Harwood, J. A Social Cognitive Theory Approach to the Effects of Mediated Intergroup Contact on Intergroup Attitudes. Journal of Broadcasting \& Electronic Media, (2007); 51(4): 615-631.

[17] Dayan, D. Particularistic Media and Diasporic Communications. Media, Ritual and Identity, (1998); 103-113.

[18] Fairweather, N. B., \& Rogerson, S. Politics and Society After De-massification of the Media. Journal of Information, communication and Ethics in Society, (2005); 3(3): 159.

[19] Mendelsohn, M., \& Nadeau, R. The Magnification and Minimization of Social Cleavages by the Broadcast and Narrowcast News Media. International Journal of Public Opinion Research, (1996); 8(4): 374-389.

[20] Yükleyen, A., \& Project Muse. Localizing Islam In Europe: Turkish Islamic Communities In Germany And The Netherlands. New York: Syracuse University Press; (2011). 